\title{
Chemical changes of human knee joint menisci in various stages of degeneration
}

\author{
J ÜRGEN HERWIG, ${ }^{1}$ EBERHARDEGNER, ${ }^{2}$ AND ECKHART BUDDECKE ${ }^{1}$ \\ From the ${ }^{1}$ Institute of Physiological Chemistry, University of Münster, and the ${ }^{2}$ Institute of Pathology, \\ Katharinenhospital Stuttgart, German Federal Republic
}

SUMMARY Human knee joint menisci graded according to degenerative alterations were submitted to chemical analysis. Normal menisci contained $72 \%$ water, $0.12 \%$ DNA, $22 \%$ collagen, and $0.8 \%$ total glycosaminoglycans with the following glycosaminoglycan distribution pattern: $40 \%$ chondroitin 6-sulphate, 10-20\% chondroitin 4-sulphate, 20-30\% dermatan sulphate, and $15 \%$ keratan sulphate. The water content increased with increasing degeneration, whereas the collagen and glycosaminoglycan contents decreased with relative increase of chondroitin 6-sulphate.

Degeneration of human knee joint menisci has been the subject of numerous morphological studies. ${ }^{12}$ In previous studies ${ }^{1}$ it was shown that the first signs of spontaneous degeneration and probably of other types of degenerative processes are found in chondrocytes that have cytoplasmic vacuoles and nuclear as well as cytoplasmic lipoid droplets. Nuclear pycnosis, karyolysis, and kariorrhexis indicate irreversible cell damage. The dystrophy of chondrocytes is accompanied by morphological changes of the intracellular substance. The degenerative processes which finally impair mechanical resistance of the tissue are characterised by a progressive fragmentation of collagen fibres and the occurrence of basophilic substances. Degeneration takes place initially and most intensely in oblique and transverse fibres, whereas longitudinal fibres are only mildly affected and later during the degeneration process. The morphological stages of degeneration in knee joint menisci are listed in Table $1 .{ }^{1}$

Biochemically the knee joint menisci represent a fibrocartilaginous tissue. Collagen type $I,{ }^{3}$ proteoglycans, ${ }^{4-6}$ and glycosaminoglycans ${ }^{78}$ have been identified and partially characterised as structural constituents, but detailed studies on the chemical composition and the metabolism of menisci are limited. In experimental animals (menisci of beagles) osteoarthritis, induced by sectioning the anterior

Accepted for publication 10 January 1984

Correspondence to Professor Dr med E. Buddecke, University of Münster, Institute of Physiological Chemistry, Waldeyerstrasse 15, D-4400 Münster, German Federal Republic. cruciate ligament, leads initially to an elevation of the water content and a reduction of the glycosaminoglycan content. $^{8}$

In the present study human knee joint menisci in various stages of degeneration were analysed for their water, collagen, and glycosaminoglycan content and for the glycosaminoglycan distribution pattern.

\section{Material and methods}

All chemicals used were of analytical grade and purchased from Boehringer (Mannheim), Merck (Darmstadt), and Serva (Heidelberg). Pronase E from Streptomyces griseus (EC 3.4.24.4) was obtained from Serva (Heidelberg), chondroitin ABC lyase (EC 4.2.2.4) and chondroitin AC lyase (EC 4.2.2.5) from Sigma (München). D-[U- $\left.{ }^{14} \mathrm{C}\right]$ glucose (specific activity $230 \mathrm{mCi} / \mathrm{mmol}$ ) was a product of the Radiochemical Centre, Amersham, Bucks (Braunschweig).

The human knee joint meniscectomy specimens were received from the Sportklinik Stuttgart (head: Dr med B. Winckelmann). After surgical removal the menisci were dissected free of their attachments and slices of about $150 \mu \mathrm{m}$ thickness were produced from the middle $2 / 3$ of each meniscus. The water content was determined from the weight difference of wet and acetone-dried specimens (wet weight about 500 $\mathrm{mg}$ ), which were then used for further analyses. Aliquots of all menisci were evaluated by morphological criteria for their grade of degeneration and distributed for chemical and metabolic analysis as listed in Table 1. 
Table 1 Criteria for the classification of stages of knee joint meniscus degeneration, ${ }^{1}$ and the age and sex distribution of meniscus specimens analysed in the present study

\begin{tabular}{|c|c|c|c|}
\hline Morphology & Stage & $\begin{array}{l}\text { Number } \\
\text { of cases }\end{array}$ & $\begin{array}{l}\text { Age (years) } \\
\text { and Sex }\end{array}$ \\
\hline $\begin{array}{l}\text { Collagen fibres parallel to each } \\
\text { other, closely set and strongly birefringent }\end{array}$ & $\begin{array}{r}0 \\
0-1\end{array}$ & $\begin{array}{l}1 \\
0\end{array}$ & $16, \mathrm{~F}$ \\
\hline $\begin{array}{l}\text { Diameter of single collagen fibres decreases, } \\
\text { basophilic substances visible between fibre bundles }\end{array}$ & 1 & 3 & $\begin{array}{l}17, \mathrm{~F} \\
21, \mathrm{M} \\
43, \mathrm{M}\end{array}$ \\
\hline \multirow[t]{2}{*}{$\begin{array}{l}\text { Collagen fibres split in longitudinal direction into } \\
\text { thinner subunits, gaps filled with basophilic substances }\end{array}$} & $1-2$ & 3 & $\begin{array}{l}22, \mathrm{~F} \\
43, \mathrm{M} \\
43, \mathrm{M}\end{array}$ \\
\hline & 2 & 1 & $25, \mathrm{M}$ \\
\hline \multirow[t]{2}{*}{$\begin{array}{l}\text { Progressive destruction of fibre bundles, split products } \\
\text { surrounded by basophilic (mucoid) substances, } \\
\text { a few fibres still preserved }\end{array}$} & $2-3$ & 3 & $\begin{array}{l}24, \mathrm{~F} \\
28, \mathrm{M} \\
50, \mathrm{~F}\end{array}$ \\
\hline & 3 & 2 & $\begin{array}{l}15, \mathrm{M} \\
42, \mathrm{M}\end{array}$ \\
\hline $\begin{array}{l}\text { Non-functioning fragments of original fibre } \\
\text { bundles embedded in basophilic substances, in } \\
\text { final stage appearing as homogeneous isotropic masses }\end{array}$ & $\begin{array}{r}3-4 \\
4\end{array}$ & 2 & $\begin{array}{l}29, \mathrm{M} \\
45, \mathrm{M} \\
12, \mathrm{~F} \\
28, \mathrm{M}\end{array}$ \\
\hline
\end{tabular}

INCUBATION EXPERIMENTS IN VITRO

After surgical removal four menisci were kept in Ringer solution at $4^{\circ} \mathrm{C}$ and used for the incubation experiments within six hours. The specimens were sliced into 0.5 to $1.0 \mathrm{~mm}$ sections. Batches, each of 200 to $300 \mathrm{mg}$ wet weight, were incubated according to the method of Handley and Phelps ${ }^{9}$ in $4 \mathrm{ml}$ of a modified buffered Krebs-Ringer solution containing $0.1 \%$ glucose. ${ }^{10}$ After incubation for 15 hours the menisci specimens were rinsed three times with icecold Ringer solution.

\section{PREPARATION OF GLY COSAMINOGLYCANS}

After determination of the acetone-dried weight the total glycosaminoglycans were isolated by standard methods. ${ }^{10}$ The tissue was exhaustively digested by incubating for 72 hours at $37^{\circ} \mathrm{C}$ with pronase $\mathrm{E}$ in $0 \cdot 1$

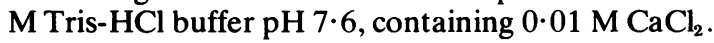
The digest was precipitated by addition of ethanol containing $1 \%$ potassium acetate, reprecipitated with ethanol and ether, dried, and redissolved in distilled water.

\section{A NALYSES}

DNA was assayed after pronase $E$ digestion and TCA precipitation according to Burton, ${ }^{11}$ hydroxyproline according to Stegeman. ${ }^{12}$ Determination of uronic acids, hexosamines, and radioactivity was as previously described. ${ }^{13}$ Total glycosaminoglycan con- tent was assayed by a colorimetric test with gentian violet modified according to Dittmann and Cremer. ${ }^{14}$

Chondroitin sulphate, dermatan sulphate, and keratan sulphate were determined by two independent methods. After digestion with chondroitin lyase $\mathrm{AC}$ and $\mathrm{ABC}$ in $50 \mathrm{mM}$ Tris $\mathrm{pH} 8 \cdot 0$, containing 60 mM sodium acetate, $3 \mathrm{mM} \mathrm{NaN}_{3}$, and $0.01 \%$ bovine serum albumin, the products were separated by descending paper chromatography in 1-butanol/1 M $\mathrm{NH}_{3} /$ glacial acid (2:1:3 by vol) and evaluated according to Saito et al. ${ }^{15}$ Keratan sulphate was assayed colorimetrically after chondroitin ABC lyase and heparin sulphate lyase digestion and ethanol precipitation. The individual glycosaminoglycans were fractionated on an analytical scale by thin layer chromatography according to Humbel and Chamoles $^{16}$ with the following modifications: after staining the material with gentian violet $(0.5 \%$ in $10 \%$ acetic acid), defined areas of the cellulose plate enclosing the visualised spots and corresponding blanks were scraped off and extracted with a solution of methanol, acetic acid, and $\mathrm{H}_{2} \mathrm{O}(5: 1: 4$, v/v) containing $7 \cdot 5 \% \mathrm{KCl}(\mathrm{w} / \mathrm{v})$. The optical density of the clear supernatant solutions was measured at $550 \mathrm{~nm}$. Hyaluronic acid was calculated by a parallel run after degradation of the total glycosaminoglycans with chondroitin $\mathrm{ABC}$ lyase from the difference of the dermatan sulphate and hyaluronic acid area with and without chondroitin ABC lyase degradation. 
Glucose and lactate were assayed in aliquots of the incubation media by enzymatic methods ${ }^{17}$ after separation by Dowex $1 \times 2$ anion exchange chromatography according to Triphaus et al. ${ }^{18}$

\section{Results}

\section{COMPOSITION OF MENISCI}

Normal human menisci (stage 0-1) contained $0 \cdot 10-0 \cdot 12 \%$ DNA, $70-75 \%$ water, $20-22 \%$ collagen, and $0 \cdot 6-0 \cdot 8 \%$ total glycosaminoglycans. The glycosaminoglycans consisted of about $40 \%$ chondroitin 6-sulphate, $20 \%$ chondroitin 4-sulphate, $20 \%$ dermatan sulphate, $15 \%$ keratan sulphate and $3 \%$ hyaluronate (Figs. 1-3). All these parameters underwent changes that were correlated with degenerative processes. In Figs. 1-3 the relevant parameters were plotted versus the stage of degeneration. However, since the histological grading system (Table 1) is only semiquantitative, the regression lines and correlation coefficients calculated from the analytical data do not provide statistical significance.

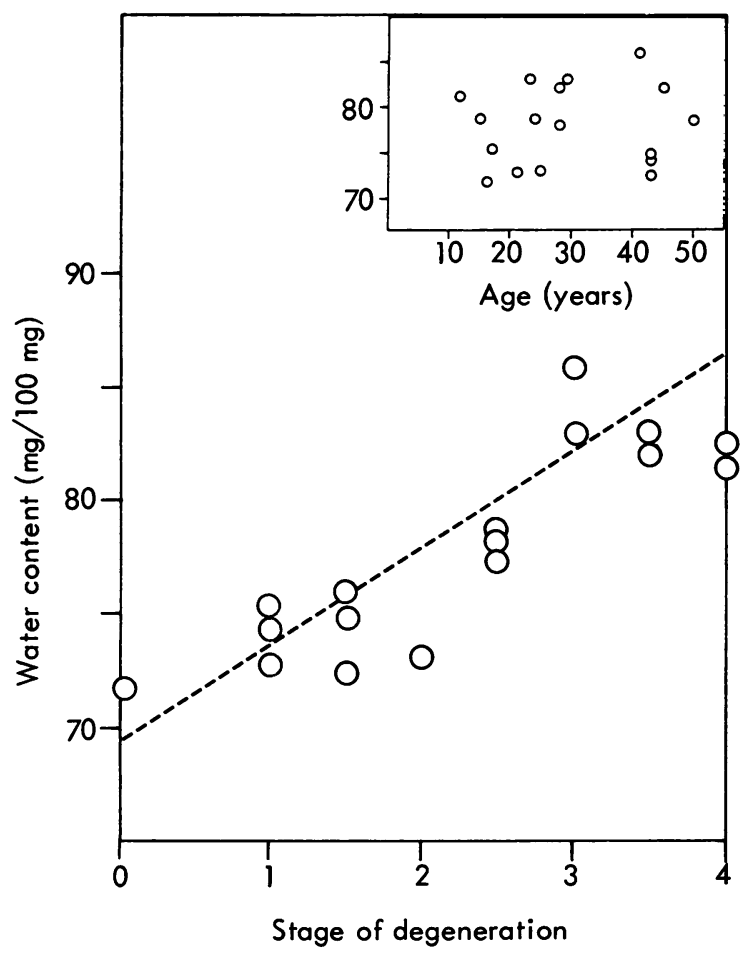

Fig. 1 Changes of water content $(\mathrm{g} / 100 \mathrm{~g}$ wet weight of tissue) of human knee joint menisci (Table 1) dependent on the stages of degeneration (correlation coefficient $r=0.91$ ). No age-dependent changes of the water content (inset) were detectable.
The water content of the menisci (Fig. 1) was correlated with the grade of degeneration and increased from about 70 to $85 \%$ of wet weight of tissue with increasing degeneration. The slope of the regression line $(3.54)$ and the correlation coefficient $(0.91)$ indicated this variation to be specific for degenerative processes.

The tissue content of collagen and total glycosaminoglycans, expressed as $\mu \mathrm{g} / \mathrm{mg}$ wet weight of tissues, showed a decrease in relation to the grade of degeneration (Fig. 2A, B). A plot of the tissue concentration, expressed as $\mu \mathrm{g} / \mathrm{mg}$ wet weight of tissue versus the grade of degeneration revealed a correlation coefficient of 0.82 for collagen and 0.68 for the total glycosaminoglycans.

The observed alterations in the water, collagen, and glycosaminoglycan content of the meniscus specimens in various degrees of degeneration were not due to age-dependent changes in these parameters. Thus, plots of the water, collagen, and glycosaminoglycans tissue concentration versus the age of the patients from whom the menisci were removed (insets of Figs. 1, 2A and 2B) showed no correlation.

When the collagen and glycosaminoglycan levels were referred to the dry weight of tissue (Fig. 3A, B), the changes in the collagen content no longer showed a consistent correlation with the pathological grading, whereas the increase of the glycosaminoglycan content was still well correlated (correlation coefficient 0.93 ).

The relative proportion of individual glycosaminoglycans was also influenced by the grade of degeneration. Fig. 4 shows that the relative proportion of chondroitin 6-sulphate increased from about $35 \%$ in normal menisci to about $55 \%$ in grossly degenerated menisci, while dermatan sulphate, chondroitin 4-sulphate, and keratan sulphate showed a modest decrease.

\section{METABOLISM OF MENISCI}

On incubation of four specimens of human meniscus under organ culture conditions in a medium containing $0 \cdot 1 \%$ [ $\left.\mathrm{U}^{14}{ }^{14} \mathrm{C}\right]$ glucose, $6-15 \mu \mathrm{mol}$ glucose were utilised per mg DNA and hour. About $60 \%$ of the utilised $\left[{ }^{14} \mathrm{C}\right]$ glucose was converted to lactate, about $3 \%$ was released as ${ }^{14} \mathrm{CO}_{2}$, and $1 \cdot 5-4 \cdot 5 \%$ was incorporated into the glycosaminoglycans. Although these results are of a preliminary nature, they suggest an increased glucose uptake and lactate formation and a raised incorporation of $\left[{ }^{14} \mathrm{C}\right]$ glucose into the glycosaminoglycan component of proteoglycans with increasing severity of degeneration. These studies are being pursued and will be reported separately when larger numbers of specimens have been examined. 

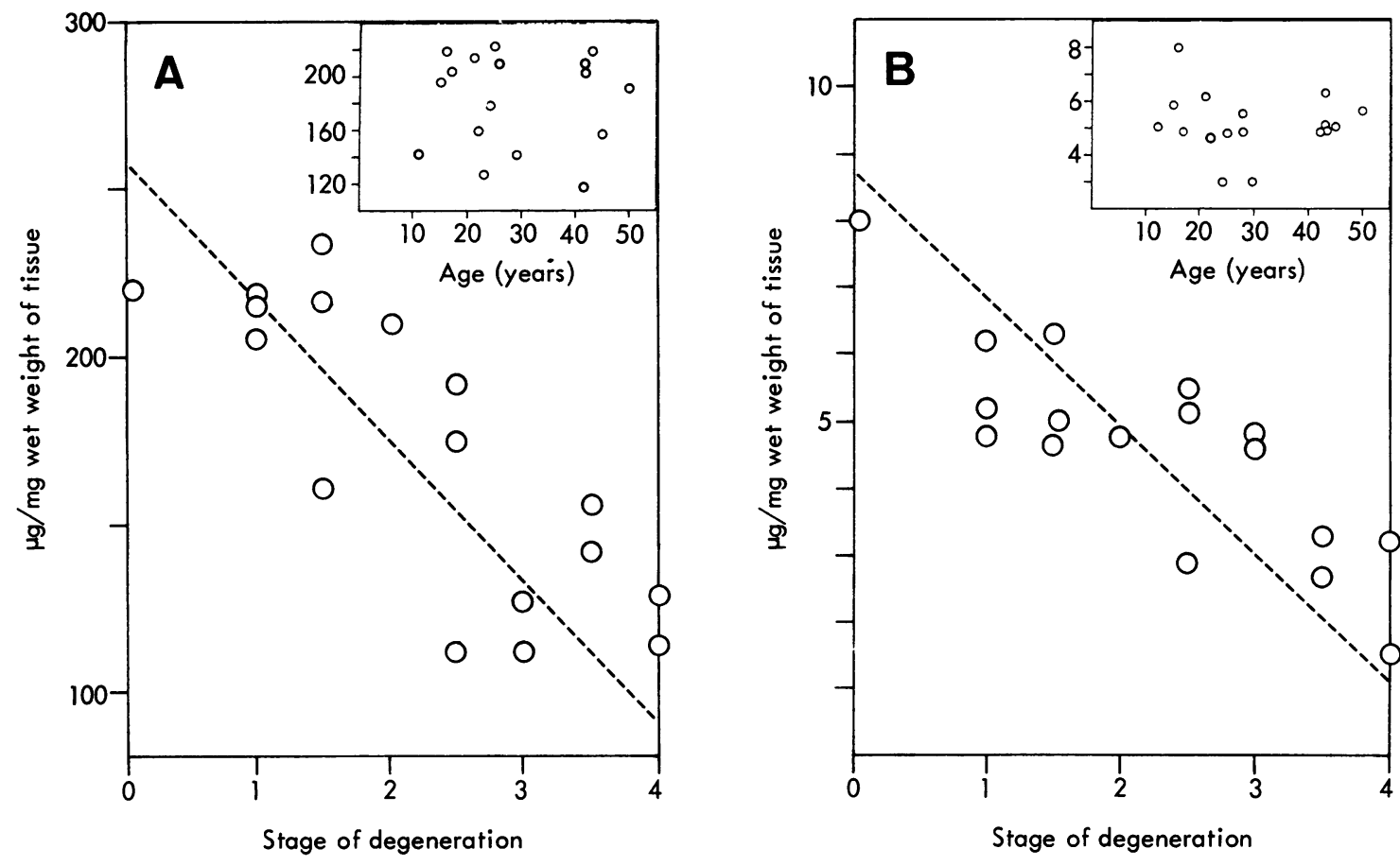

Fig. 2 Content of collagen $(A)$ and total glycosaminoglycans $(B)$ expressed as $\mu \mathrm{g} / \mathrm{mg}$ wet weight of tissue correlated with the grade of meniscus degeneration (correlation coefficients $0.82(A)$ and $0.68(B)$ ). Inset shows age-dependent variations.

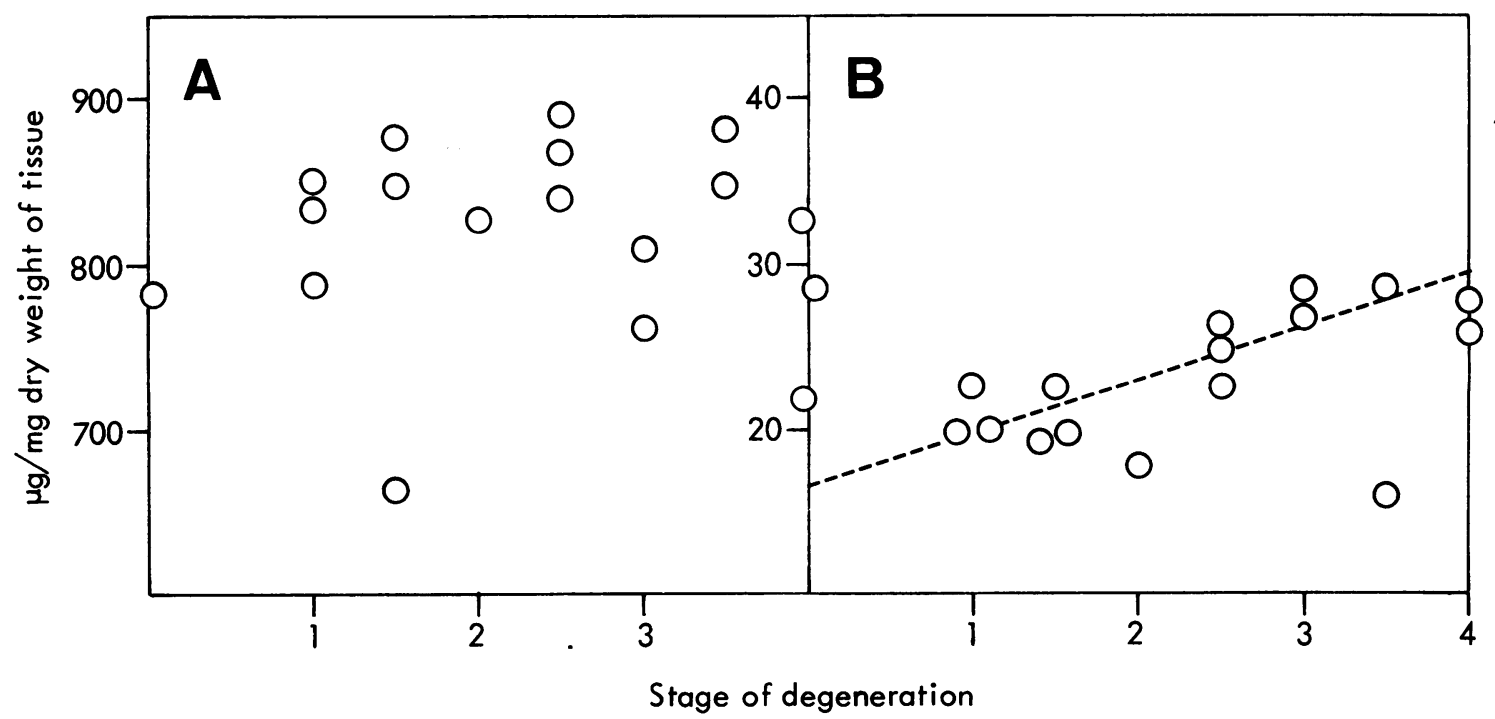

Fig. 3 Content of collagen (A) and total glycosaminoglycans $(B)$ expressed as $\mu \mathrm{g} / \mathrm{mg}$ dry weight of tissue correlated with the grade of meniscus degeneration. 

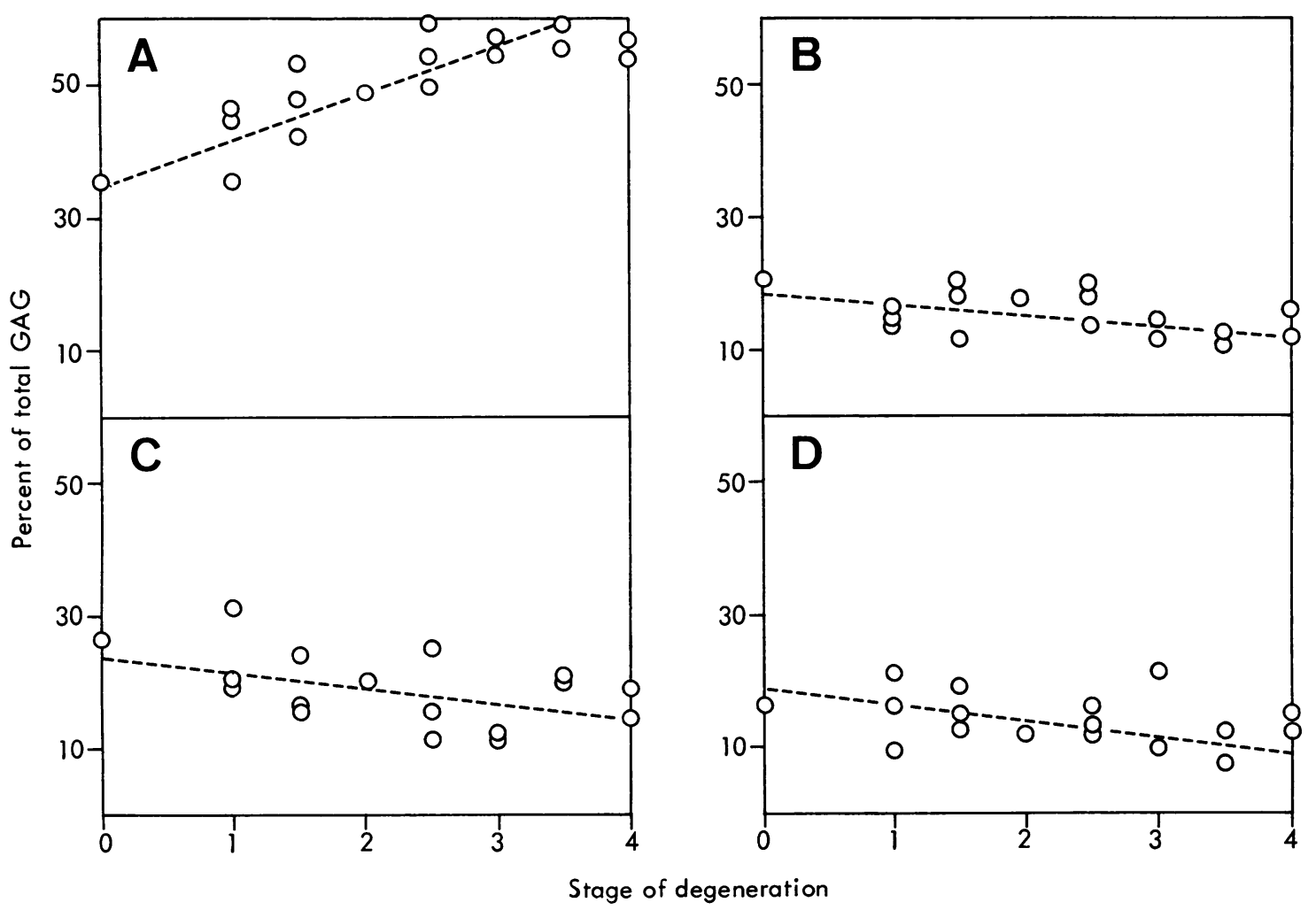

Fig. 4 Changes of the relative proportion of individual glycosaminoglycans ( $G A G)(\mathrm{mg} / 100 \mathrm{mg}$ glycosaminoglycans) dependent on the stage of degeneration. A, chondroitin-6-sulphate ( $r=0.84) ; B$, chondroitin-4-sulphate $(r=0.58) ; C$, dermatan-sulphate $(r=0.46)$; and $D=k e r a t a n$ sulphate $(r=0.54)$. Separation and quantification of glycosaminoglycans are described in 'Material and methods'.

\section{Discussion}

The fibrocartilage of knee menisci is a functionally specialised tissue that may play a role in weightbearing, nutrition, and lubrication of the articular cartilage and in joint stability.

Degenerative changes of knee menisci frequently result from trauma to the joint or are associated with joint diseases; in other cases they arise after chronic overload or even spontaneously. Therefore the present study was addressed to an investigation of the changes in chemical composition and metabolism of the menisci due to degenerative processes. In accordance with previous studies ${ }^{1}$ we used a grading of degenerative alterations into four stages.

Adult human knee menisci were found to possess proteoglycan molecules of similar size and glycosaminoglycan content to those present in articular cartilage ${ }^{45}$ although tissue concentrations were considerably lower. As Fig. 2 shows, the glycosaminoglycan concentration ranged from $0 \cdot 2$ to $0.8 \%$ of wet weight of meniscus tissue. In normal menisci (stage $0-1$ ) about $80 \%$ of the total glycosaminoglycans were identified as chondroitin 4-sulphate, chondroitin 6-sulphate, and dermatan sulphate. This result is in reasonable accordance with the data of Habuchi et al. ${ }^{19}$ and Karube et al. ${ }^{20}$ who found $50-60 \%$ for the sum of these glycosaminoglycans, and it is comparable with values for glycosaminoglycans of canine menisci, which were reported to consist of $90 \%$ chondroitin sulphate and dermatan sulphate.?

In the present investigation a significant decrease of the glycosaminoglycan content and an increase of the water content with increasing meniscus degeneration was noted. This result bears similarities to those of Adamset al. ${ }^{8}$ who found that induction of osteoarthritis in beagles by sectioning the anterior cruciate ligament caused a decrease in the glycosaminoglycan level and an increase in the water content of the 
menisci after one week. After 3-18 months the glycosaminoglycan content reverted to normal values and rose above normal after 15-18 months. These changes may be evidence for a regeneration capacity of the canine meniscus cartilage.

We found a decrease of the collagen content of the wet weight of tissue in relation to degeneration, but it was no longer detectable when the collagen concentration was expressed per dry weight unit of tissue. The glycosaminoglycan content of the dry weight of menisci, however, tended to increase (Fig. 3B), thus giving evidence for an accumulation of water binding proteoglycans in degenerated human menisci.

No typing of the collagen present in human knee joint menisci was made. It is, however, possible that the type of collagen produced by the menisci may alter in response to injury or disease. For instance it has been suggested that in osteoarthrosis type I collagen is formed in articular cartilage,$^{21}$ which normally contains only type II collagen.

The authors are greatly indebted to Mrs I. Klein for her excellent technical assistance.

\section{References}

1 Egner E. Knee joint meniscal degeneration as it relates to tissue fiber structure and mechanical resistance. Pathology, Research and Practice 1982; 173: 310-24.

2 Könn G, Oelling W P. Zur Morphologie und Beurteilung der Veränderungen an den Kniegelenksmenisken. Pathologe 1980; 1: 206-13.

3 Eyre D R, Muir $\mathbf{H}$. The distribution of different molecular species of collagen in fibrous, elastic and hyaline cartilages of the pig. Biochem J 1975; 151: 595-602.

4 McNicol D, Roughley P J. Extraction and characterization of proteoglycan from human meniscus. Biochem $J$ 1980; 185: 705-13.

5 Roughley P J, McNicol D, Santer V, Buckwalter J. The presence of cartilage-like proteoglycan in the adult human meniscus. Biochem J 1981; 197: 77-83.
6 Stanescu V, Maroteaux P, Sobczak E. Proteoglycan populations of baboon (Papio papio) cartilages from different anatomical sites. Gel electrophoretic analysis of dissociated proteoglycans and of fractions obtained by density gradient centrifugation. Biochim Biophys Acta 1980; 629: 371-81.

7 Adams M E, Muir $H$. The glycosaminoglycans of canine menisci. Biochem J 1981; 197: 385-9.

8 Adams M E, Billingham ME J, Muir $\mathrm{H}$. The glycosaminoglycans in menisci in experimental and natural osteoarthritis. Arthritis Rheum 1983; 26: 69-76.

9 Handley C J, Phelps C F. The biosynthesis in vitro of chondroitin sulphate in neonatal rat epiphyseal cartilage. Biochem $J$ 1972; 126: 417-32.

10 Kresse H, Buddecke E. Stoffwechselheterogenität von Chondroitin-4-sulfat-Proteinen und Kollagenstoffwechsel in Rindernasenknorpel. Hoppe-Seylers Z Physiol Chem 1968; 349: 1497-506.

11 Burton K. A study of the conditions and mechanism of the diphenylamine reaction for the colorimetric estimation of deoxyribonucleic acid. Biochem J 1956; 62: 315-23.

12 Stegemann H. Mikrobestimmung von Hydroxyprolin mit Chloramin- $T$ und p-Dimethylaminobenzaldehyd. HoppeSeylers Z Physiol Chem 1958; 311: 41-5.

13 von Figura K, Kiowski W, Buddecke E. Differently labelled glucosamine-precursor pools for the biosynthesis of hyaluronate and heparin sulfate. Eur J Biochem 1973; 40: 89-94.

14 Dittmann G, Cremer H D. Chondroitinschwefelsäure in Knorpel, Knochen und Zähnen. Biochem Z 1956; 327: 368-76.

15 Saito H, Yamagata T, Suzuki S. Enzymatic methods for the determination of small quantities of isomeric chondroitin sulfates. J Biol Chem 1968; 243: 1536-42.

16 Humbel R, Chamoles N A. Sequential thin layer chromatography of urinary acidic glycosaminoglycans. Clin Chim Acta 1972; 40: $290-3$.

17 Bergmeyer H U, ed. Methoden der enzymatischen Analysen. 2nd ed. Weinheim: Verlag Chemie, 1970: 1163, 1425.

18 Beckmann J, Rodegerdts U, Buddecke E. ${ }^{14} \mathrm{C}$-glucose and ${ }^{35} \mathrm{~S}$ metabolism of pig epiphyseal cartilage and its variations after osteotomy.J Bone Joint Surg 1975; 57-B: 506-10.

19 Habuchi H, Yamagata T, Iwata H, Suzuki S. The occurrence of a wide variety of dermatan sulfate-chondroitin sulfate copolymers in fibrous cartilage. $J$ Biol Chem 1973; 248: 6019-28.

20 Karube S, Shoji M, Burkes B, D' Ambrosia R D, Chuinard R G, Saer J K. Glycosaminoglycans in human menisci. Surg Forum 1979; 30: 485-6.

21 Nimni M, Deshmukh K. Differences in collagen metabolism between normal and osteoarthritic human articular cartilage. Science 1973; 181: 751-2. 